\title{
Microwave Synthesis of Some New 1,3-Oxazepine Compounds as Photostabilizing Additives for Pmma Films
}

\author{
Ayad Hameed \\ Department of Chemistry, College of Education, Tikrit University, Tikrit-Iraq.
}

\begin{abstract}
The work presented in the current research is concerned with the synthesis of four new compounds containing 1,3-oxazepine and 1,3,4-oxadiazole [1-4] by microwave assisted organic synthesis method through the condensation reaction of 2-[4-(arylidene) phenyl-1,3,4-oxadiazole-5thiole] with maleic anhydride under variable microwave power $(180,510)$ watt. The structure of the synthesized compounds was characterized using available spectroscopic methods $\left(\mathrm{H}^{1}\right.$-NMR, FTIR) and the results obtained are agreement with the proposed structures assigned to these compounds.

The photostabilization of poly (methyl methacrylate) PMMA films by of 1,3-Oxazepine compounds [1-4] was investigated. The PMMA films containing concentration of [1-4] $0.5 \%$ by weight were produced by the casting method from chloroform solvent. The photostabilization activities of these compounds were determined by monitoring the hydroxyl index with irradiation time. The changes in viscosity average molecular weight of PMMA with irradiation time were also tracked (using benzene as a solvent). The quantum yield of the chain scission $\left(\Phi_{\mathrm{cs}}\right)$ of these compounds in PMMA films was evaluated and found to range between $4.20 \times 10^{-5}$ and $8.76 \times 10^{-5}$. Results obtained showed that the rate of photostabilization of PMMA in the presence of the additive followed the trend:

$[1]>[2]>[3]>[4]$

According to the experimental results obtained, several mechanisms were suggested depending on the structure of the additive. Among them, UV absorption, peroxide decomposer and radical scavenger for photostabilizer mechanisms were suggested.
\end{abstract}

Keywords: Microwave synthesis, 1,3-oxazepine, 1,3,4-oxadiazole, photochemistry, PMMA, photostabilizer, UV absorber

\section{Introduction}

Microwave assisted organic reaction enhancement (MORE) is now days a well established technique for synthesis of various heterocyclic compounds (1-3) through cycloaddition reactions, especially in the cases where high temperature are required, these synthesis can be carried out safely in microwave reactor with remarkable rate enhancement, these mainly due to the super heating effect. The ability of microwave to rapidly heat the reaction much above the boiling points of the solvent ${ }^{(4,5)}$. There is a great interest at present in the photo-oxidative degradation of polymeric materials because macromolecules have increasingly widespread commercial applications. Polymeric synthetic, semi synthetic and natural are when exposed to the environment ${ }^{(6)}$. All commercial organic polymers degrade in air when exposed to sunlight as the energy of sunlight is sufficient to cause the breakdown of polymeric $\mathrm{C}-\mathrm{C}$ bonds as a consequence of degradation. The resulting smaller fragments do not contribute effectively to the mechanical properties and the polymeric article because brittle. Thus the life of thermoplastics for outdoor applications becomes limited due to weathering ${ }^{(7)}$. Almost all synthetic polymers require stabilization against the adverse effect with the development of synthetic resins it became necessary to look for ways and means to prevent, or at least reduce, the damage caused by the environmental parameters, light, air and heat. This can be achieved through addition of special, chemicals, light stabilizers or UV stabilizers, that have to be adjusted to the nature of the resin and the specific application considered. The photostabilization of polymers may be achieved in many ways. The following stabilizing systems have been developed. Which depend on the action of stabilizer :- (1) Light screeners, (2) UV absorbers, (3) excited state quenchers, (4) peroxide decomposers, and (5) Free radical scavengers, of these it is generally believed that types 3, 4 and 5 are the 
most effective ${ }^{(8)}$. Most or, indeed all stabilizers are believed to be multifunctional in their mode operation. This view is complicated by the fact that mechanism involved in photooxidation and these, in turn depend on the polymer structure and other variables, such as manufacturing, operation, processing, conditions, etc. ${ }^{(9)}$.

As part of our on-going research on the photostabilization of polymers, the photostabilization of PMMA was studied using a new four heterocyclic compounds containing 1,3-oxazepine and 1,3,4-oxadiazole and we hope that the incorporation of these two heterocyclic units may enhance the photostability of PMMA.

\section{Experimental}

\subsection{Organic synthesis part:}

Melting points were measured on an Electro thermal melting point apparatus sartorius BL - 210S and were uncorrected. The IR - spectra were recorded on Perkins-Elmer Fourier-Transforme Infrared Spectrophotometer (FR-IR) as potassium bromide pelts.

$\mathrm{H}^{1}$-NMR spectra were performed on a Bruker - NMR, ultra shield (300) $\mathrm{MHz}$, Switzerland spectrometer using $\mathrm{D}^{6}$-DMSO as solvent and TMS as internal standard. All the chemicals used in this research (solid, liquid) were obtained from Merck, GCC, Fluka and BDH companies. Compounds (A-D) namely: 5-(4-arylidene)-phenyl-1,3,4-oxadiazole was synthesized using a published methods ${ }^{(10)}$. The
1,3-Oxazepine compounds were all prepared by the method previously described ${ }^{(11)}$.

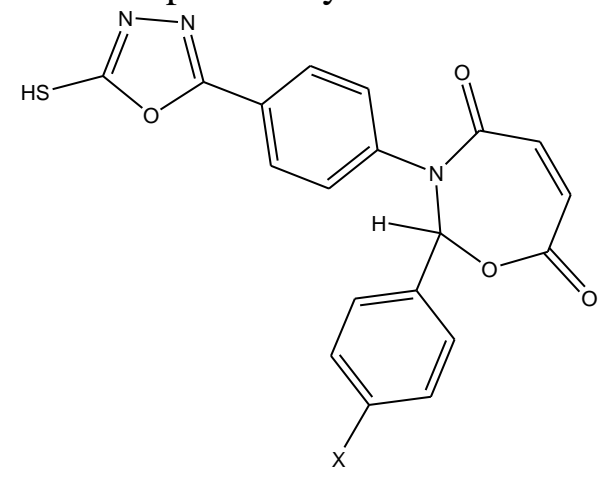

where $\mathrm{X}=-\mathrm{OH},-\mathrm{N}(\mathrm{CH} 3) 2,-\mathrm{H},-\mathrm{Cl}$
[1],
[2],
[3], [4]

2.1.1 General procedure for the synthesis of compounds (1-4). (Z)-2,3-dihydro-(5mercapto-1,3,4-oxadiazol-2-yl)phenyl-2-(substituted)-1,3,4oxazepine- 4,7-dione.

Recently a new method which has been discovered involves direct addition of maleic anhydride to the $(\mathrm{C}=\mathrm{N})$ double bond of Schiff base, and according to this method four new compounds were synthesized having the above general name using microwave approach instead of refluxing method ${ }^{(11)}$.

A mixture of (0.001 mole) of compounds (A-D) and (0.001 mole) of maleic anhydride were ground with a mortar, mixed, dried and subjected to microwave irradiation for (2-3) minutes, after completion the reaction mixture was cooled to room temperature and the solid obtained was recrystallized twice from absolute ethanol, some of physical data for these four compounds are listed in Table (1).

Table (1)

Physical properties of 1,3-oxazepine-4,7-dion compounds (1-4).

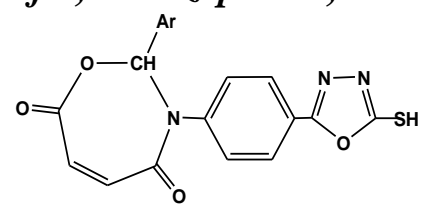

\begin{tabular}{|c||c||c||c||c||c||c|c||}
\hline $\begin{array}{c}\text { Comp. } \\
\text { No. }\end{array}$ & Ar. & Color & $\begin{array}{c}\text { Yield } \\
\%\end{array}$ & $\begin{array}{c}\text { Molecular } \\
\text { formula }\end{array}$ & $\begin{array}{c}\text { M.p. } \\
{ }^{\circ} \boldsymbol{C}\end{array}$ & $\begin{array}{c}\text { M.W.I } \\
\text { Power }\end{array}$ & $\begin{array}{c}\text { Reaction } \\
\text { time (min.) }\end{array}$ \\
\hline \hline 1 & & Orange & 79 & $\mathrm{C}_{19} \mathrm{H}_{13} \mathrm{~N}_{3} \mathrm{O}_{5} \mathrm{~S}$ & $245-248$ & 510 & 2 \\
\hline 2 & & Orange & 82 & $\mathrm{C}_{21} \mathrm{H}_{18} \mathrm{~N}_{4} \mathrm{O}_{4} \mathrm{~S}$ & $250-254$ & 180 & 3 \\
\hline 3 & yellow & 87 & $\mathrm{C}_{19} \mathrm{H}_{13} \mathrm{~N}_{3} \mathrm{O}_{4} \mathrm{~S}$ & $200-202$ & 180 & 2 \\
\hline 4 & & Orange & 83 & $\mathrm{C}_{19} \mathrm{H}_{13} \mathrm{~N}_{3} \mathrm{O}_{4} \mathrm{SCl}$ & $229-231$ & 180 & 3 \\
\hline
\end{tabular}




\subsection{Photostabilizing part}

\subsubsection{Films preparation}

Commercial PMMA was re-precipitated from chloroform solution by alcohol several times and finally dried under vacuum at room temperature for (24) h. Fixed concentrations of PMMA solution $(5 \mathrm{~g} / 100 \mathrm{ml})$ in chloroform were used to prepare polymer films with (40) $\mu \mathrm{m}$ thickness (measured by a micrometer type 2610 A, Germany). The prepared comppounds $(0.5 \%$ concentrations $)$ were added to the films starting at 0 concentrations (blank). It was necessary to control the hygrometry and the rate of evaporation of solvent during casting to maintain good optical quality and very limited turbidity. The film transmission should be greater than $80 \%$ in the near-UV range. The films were prepared by evaporation technique at room temperature for $24 \mathrm{~h}$. To remove the possible residual chloroform solvent, film samples were further dried at room temperature for (3) $\mathrm{h}$ under reduced pressure. The films were fixed on stands especially used for irradiation. The stand is provided with an aluminum plate (0.6 $\mathrm{mm}$ in thickness) supplied by Q-panel company.

\subsubsection{Irradiation experiments}

\subsubsection{Accelerated testing technique}

Accelerated weather-meter Q UV tester (Q panel, company, USA), was used for irradiation of polymers films. The accelerated weathering tester contains stainless steel plate, which has two holes in the front side and a third one behind. Each side contains a lamp (type Fluorescent Ultraviolet Lights) 40W each. These lamps are of the type UV-B 313 giving spectrum range between 290 and $360 \mathrm{~nm}$ with a maximum wavelength $313 \mathrm{~nm}$. The polymer film samples were vertically fixed parallel to the lamps to make sure that the UV incident radiation is perpendicular on the samples. The irradiated samples were rotated from time to time to ensure that the intensity of light incident on all samples is the same.
2.2.3 Photodegradation measuring methods

\subsubsection{Measuring the photodegradation rate of polymer films using infrared spectrophotometery}

The degree of photodegradation of polymer film samples was followed by monitoring FTIR spectra in the range 4000$400 \mathrm{~cm}^{-1}$ using FTIR 8300 Shimadzu Spectrophotometer. The position of hydroxyl absorption is specified at $3430 \mathrm{~cm}^{-1}$.

The progress of photo-degradation during different irradiation times was followed by observing the changes in hydroxyl peak. Then hydroxyl index $\left(\mathrm{I}_{\mathrm{OH}}\right)$ was calculated by comparison of the FTIR absorption peak at $3430 \mathrm{~cm}^{-1}$ with reference peak at $1450 \mathrm{~cm}^{-1}$, respectively. This method is called band index method which includes:

$$
I_{s}=\frac{A_{s}}{A_{r}}
$$

where $\left(A_{s}\right)$ is the absorbance of peak under study, $\left(A_{r}\right)$ is absorbance of reference peak, and $\left(\mathrm{I}_{\mathrm{s}}\right)$ is the index of group under study. Actual absorbance, the difference between the absorbance of top peak and base line (A Top Peak - A Base Line) is calculated using the Base Line method ${ }^{(12)}$.

\subsubsection{Determination of average molecular} weight $\left(\overline{\mathrm{M}}_{\mathrm{v}}\right)$ using viscometry method

The viscosity property was used to determine the average molecular weight of polymer, using the Mark-Houwink relation $(13,14)$

$[\eta]=K \bar{M}_{v}^{x}$

where [ $\eta]$ is the intrinsic viscosity, $K$ and $\alpha$ are constants depend upon the polymersolvent system at a particular temperature. The intrinsic viscosity of a polymer solution was measured with an Ostwald U-tube viscometer. Solutions were made by dissolving the polymer in a solvent $(\mathrm{g} / 100 \mathrm{ml})$ and the flow times of polymer solution and pure solvent are $(\mathrm{t})$ and $\left(\mathrm{t}_{\mathrm{o}}\right)$ respectively. Specific viscosity $\left(\eta_{\mathrm{sp}}\right)$ was calculated as follows:

$$
\eta_{r e}=\frac{t}{t_{o}}
$$

where $\eta$ re is the relative viscosity. 
$\eta_{s p}=\eta_{r e}-1$

The single-point measurements were converted to intrinsic viscosities by the relation (2).

$$
[\eta]=(\sqrt{2} / c)\left(\eta_{s p}-\ln \eta_{r e}\right)^{1 / 2}
$$

where $\mathrm{C}$ is the concentration of polymer solution $(\mathrm{g} / 100 \mathrm{ml})$. By applying Eq. (5), the molecular weight of degraded and undergirded polymer can be calculated. Molecular weights of PMMA with and without additives were calculated from intrinsic viscosities measured in benzene solution using Eq. (2). The quantum yield of main chain scission $\left(\Phi_{\mathrm{cs}}\right)^{(15)}$ was calculated from viscosity measurement using the following relation:

$$
\phi_{c s}=\left(C A / \bar{M}_{v, 0}\right)\left[\left(\left[\eta_{0}\right] /[\eta]\right)^{1 / \alpha}-1\right] / I_{0} t
$$

where $\mathrm{C}$ is the concentration, A is Avogadro's number, $\left(\overline{\mathrm{M}}_{\mathrm{v}, \mathrm{o}}\right)$ is initial viscosity-average molecular weight, $\left[\eta_{\mathrm{o}}\right]$ is intrinsic viscosity of PMMA before irradiation, $\left(\mathrm{I}_{0}\right)$ is incident intensity, and $t$ is the irradiation time in second.

\section{Results and Discussion}

In the present work four new compounds of 1,3-oxazepines, general naming: (Z)-2,3dihydro-3-[4-(5-mercapto-1,3,4-oxadiazole-2yl)-phenyl-2-(substituted)-1,3-oxazepine-4,7dione] [1-4] were prepared in good yields through the cycloaddition reactions of compounds (A-D), 2-(4-arylidene)-phenyl1,3,4-oxadiazole-5-thiol with maliec anhydride under microwave irradiation using a domestic microwave oven. All of the products obtained in good yields (70-87) $\%$ and the optimum period of reaction time was found to be (2-3) min.
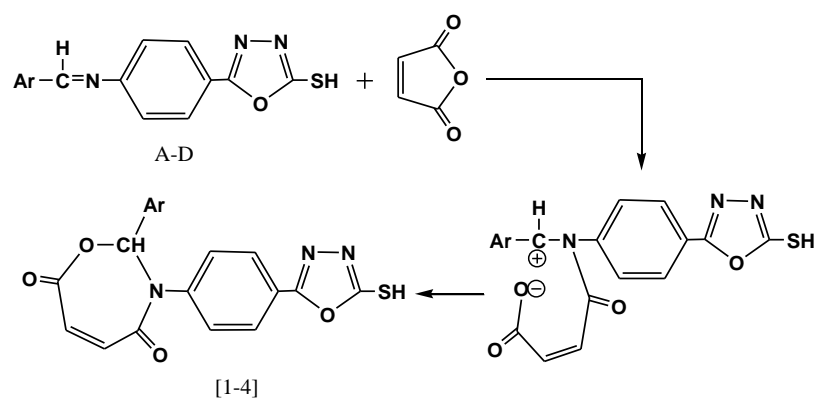

The structures of these four compounds were characterized by spectral data, the IR-spectra of these compounds shows the appearance of the absorption bands at (17041610) $\mathrm{cm}^{-1}$ characteristic to $(\mathrm{C}=\mathrm{O})$ of (lactone -lactam), and the disappearing the two absorption bands at (1950-1800) $\mathrm{cm}^{-1}$ of pure maleic anhydride. Table (2) shows the most IR-spectral data.

The $\mathrm{H}^{1}$-NMR spectrum of compound (1) showed the following characteristic signals: one broad singlet in the region (9.8) $\mathrm{ppm}$ integrating for one proton which assigned to $(-\mathrm{O}-\mathrm{H})$ being broad and shifted to the low field, this probably due to intermolecular hydrogen bonding. Also the spectrum showed one singlet in the region (10.5) ppm integrating for one proton which assigned to $(\mathrm{N}-\mathrm{H})$. The proton of $(\mathrm{S}-\mathrm{H})$ group exhibited singlet in the region $(2.8-3.0) \mathrm{ppm}$ and thus explain the occurring of the tautomerism phenomena in this compound:

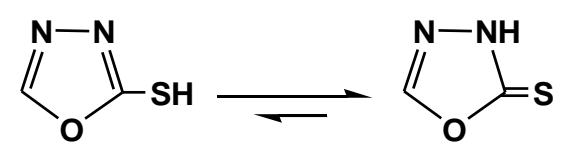

The two protons of cis olefine $(\mathrm{CH}=\mathrm{CH})-$ for oxazepine ring exhibit signals at (6.496.94) and appeared as doublet-doublet. The resonance peaks appeared at (7.4-7.7) ppm doublet-doublet could be assigned to benzene ring attached to oxazepine and oxadiazole rings.

The collection of spectral data (IR, $\mathrm{H}^{1}$-NMR) gave good evidence for structures given to these compounds. Table (3) showed $\mathrm{H}^{1}$-NMR spectral data for [1-4] compounds. 
Table (2)

The IR characteristic bands and their locations of the 1,3,4-oxadiazole-1, 3-oxazepine compounds [1-4].

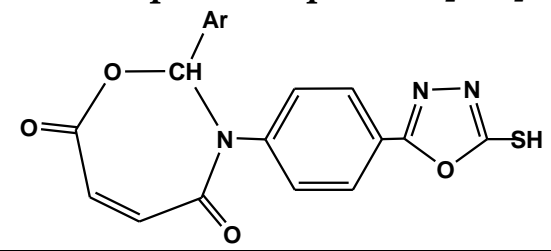

\begin{tabular}{|c|c|c|c|c|c|c|c|}
\hline \multirow[b]{2}{*}{$\begin{array}{c}\text { Comp. } \\
\text { No. }\end{array}$} & \multirow[b]{2}{*}{$A r$} & \multicolumn{6}{|c|}{ IR spectral data $\left(\mathrm{cm}^{-1}\right)$} \\
\hline & & $\begin{array}{l}\text { C=O str. } \\
\text { Lacton, } \\
\text { Lactam }\end{array}$ & $C=N$ & $\begin{array}{l}C=C-C O- \\
\text { Str. cyclic }\end{array}$ & $\begin{array}{l}\text { C-O-O } \\
\text { Sym., } \\
\text { Asym. } \\
\end{array}$ & $\begin{array}{c}\text { C-H } \\
\text { Arom. }\end{array}$ & Others \\
\hline 1 & & 1689,1660 & 1598 & $\begin{array}{l}\text { Overlapped } \\
\text { with } \mathrm{C}=\mathrm{O} \\
\text { for lacton }\end{array}$ & 1066,1166 & 3060 & $\begin{array}{l}3035(\mathrm{O}-\mathrm{H}) \text { str. } \\
\text { being broad due } \\
\text { to hydrogen } \\
\text { bonding }\end{array}$ \\
\hline 2 & & 1704,1640 & 1598 & - & 1163,1066 & 3076 & 2927 (C-H aliph.) \\
\hline 3 & & $\begin{array}{c}1691,1610 \\
\text { (overlap } \\
\text { with C=N) } \\
\end{array}$ & 1598 & 1610 & 1029,1174 & 3087 & $\begin{array}{c}740(\mathrm{C}-\mathrm{H} \\
\text { bending, out of } \\
\text { plane for } p \text {-sub.) } \\
\end{array}$ \\
\hline 4 & & 1703,1660 & - & 1517 & 1179,1068 & 3078 & $690(\mathrm{C}-\mathrm{Cl})$ \\
\hline
\end{tabular}

Table (3)

The $H^{1}$-NMR spectra data $(\delta$, ppm) of the 1,3,4-oxadiazole-1,3-oxazepine compounds [1-4].

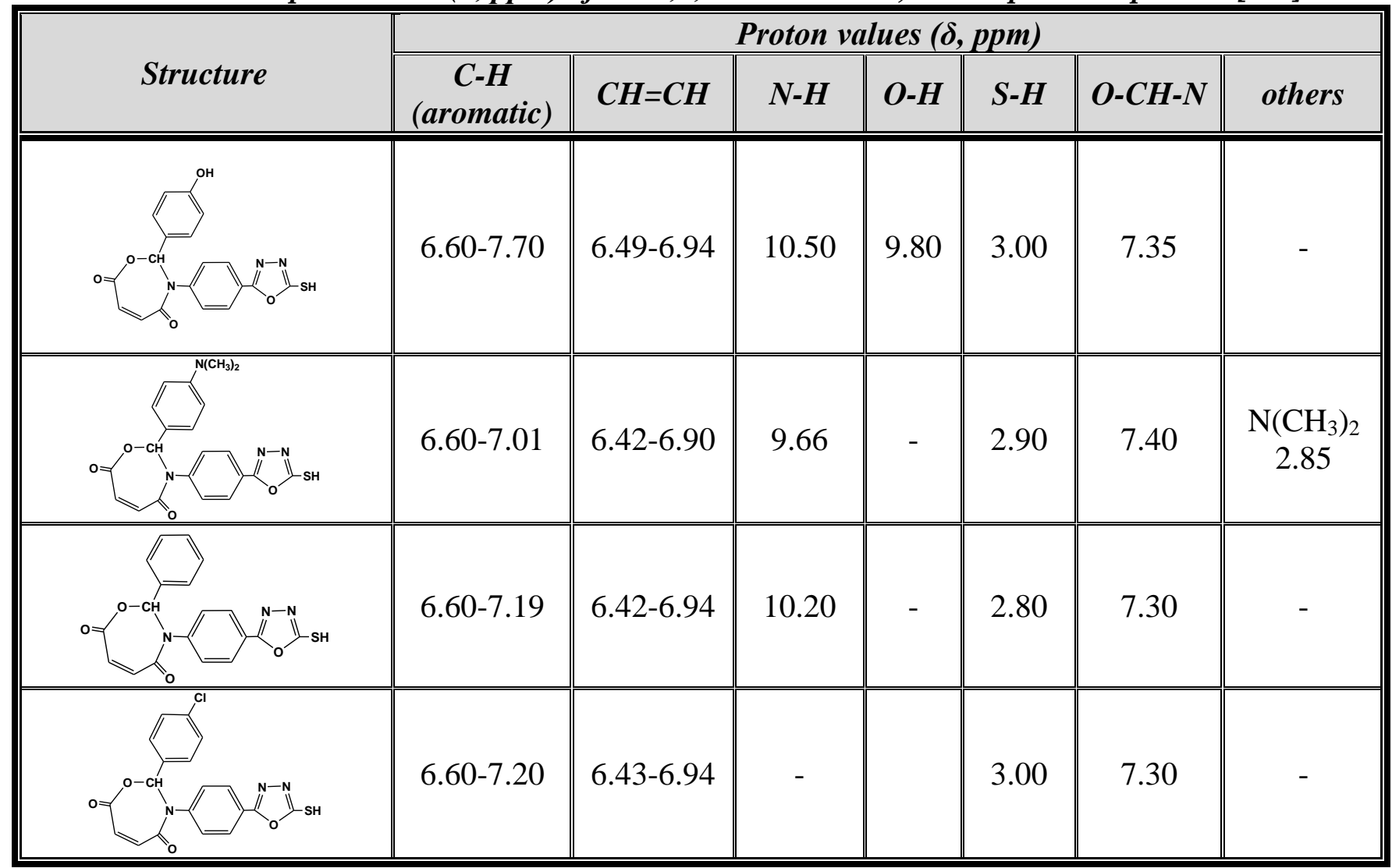


3. Photodegradation mechanism of PMMA.

The photochemical degradation steps for PMMA may be outlined as follows:
1. Formation free radicals $\left(\mathrm{A}_{1}\right)$ and $\left(\mathrm{A}_{2}\right)$ which were produced through the homolytic cleavage of $\left(\mathrm{C}-\mathrm{CH}_{3}\right)$ and $\left(\mathrm{C}-\mathrm{COOCH}_{3}\right)$ bonds respectively

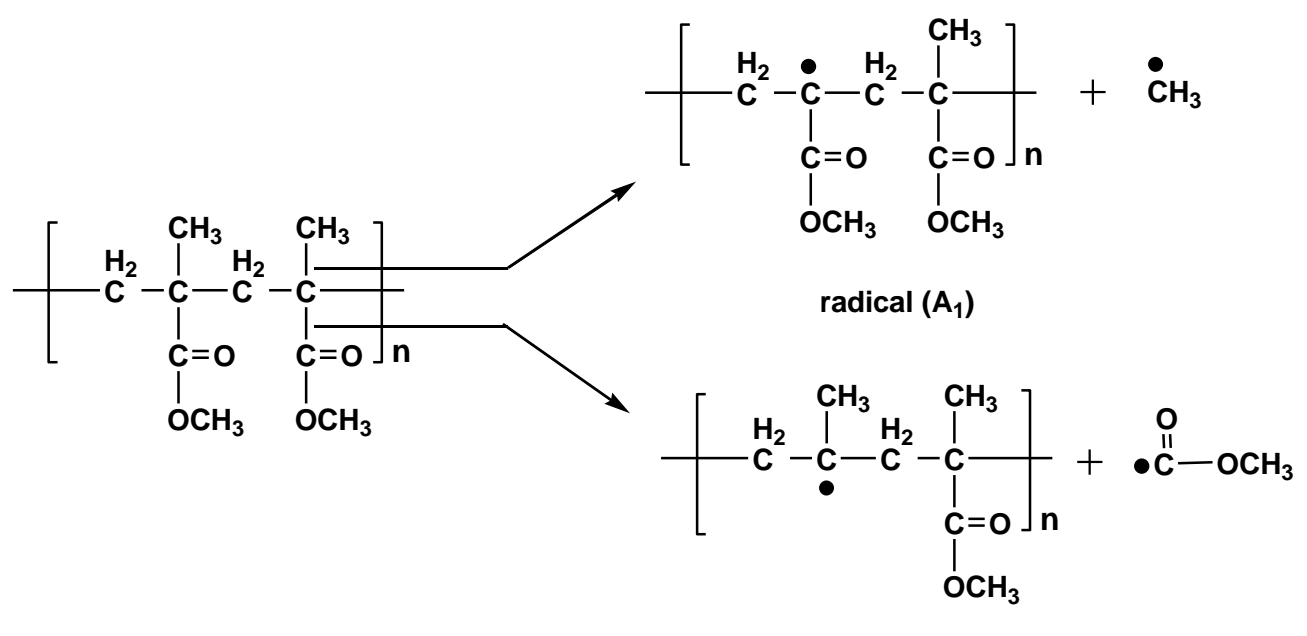

radical $\left(A_{2}\right)$

2. The reaction of free radicals type $\left(\mathrm{A}_{1}, \mathrm{~A}_{2}\right)$

with oxygen molecules to produce peroxy

radical type $\left(\mathrm{B}_{1}, \mathrm{~B}_{2}\right)$ respectively.

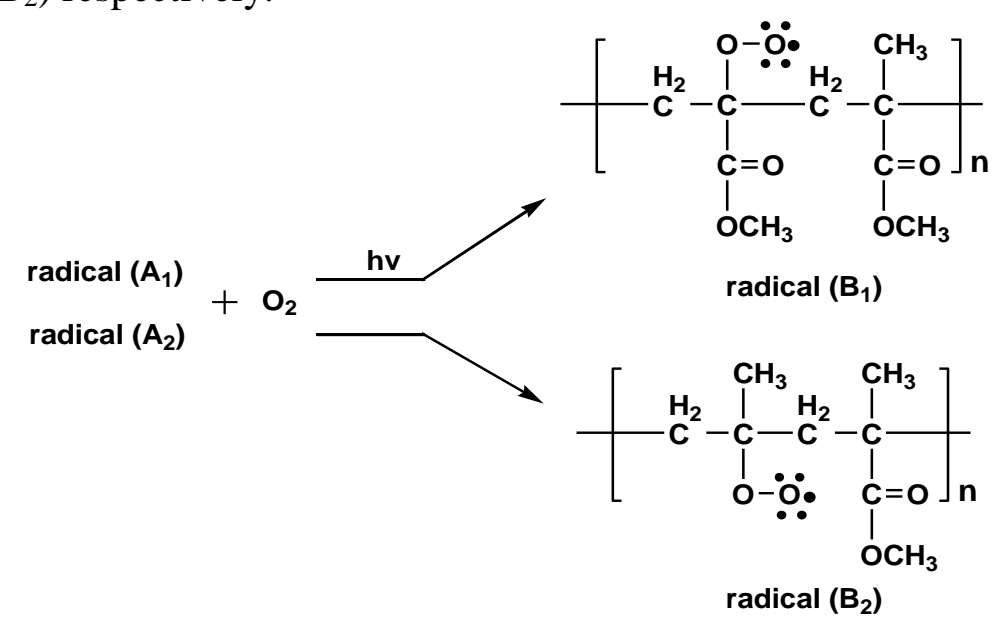

3. Abstraction of hydrogen atom from $(\mathrm{P}-\mathrm{H})$ polymer chain by the peroxy radicals type

$\left(\mathrm{B}_{1}, \mathrm{~B}_{2}\right)$ afforded hydroperoxide polymers type $\left(\mathrm{C}_{1}, \mathrm{C}_{2}\right)$.

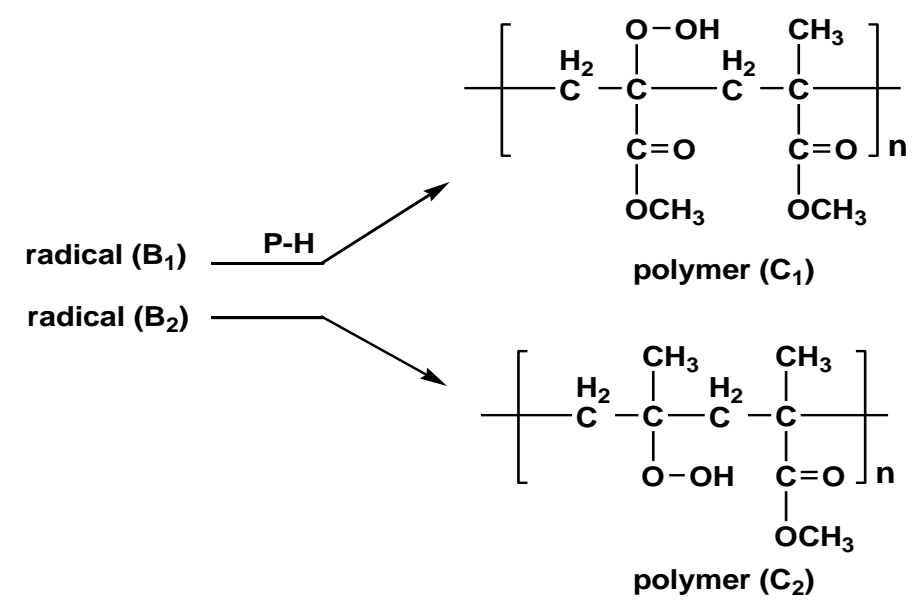


4. Homolytic cleavage of $(\mathrm{O}-\mathrm{OH})$ of the hydroperoxy polymer $\left(\mathrm{C}_{1}, \mathrm{C}_{2}\right)$ formed new free radical polymers (polymer oxy radical) type $\left(\mathrm{D}_{1}, \mathrm{D}_{2}\right)$

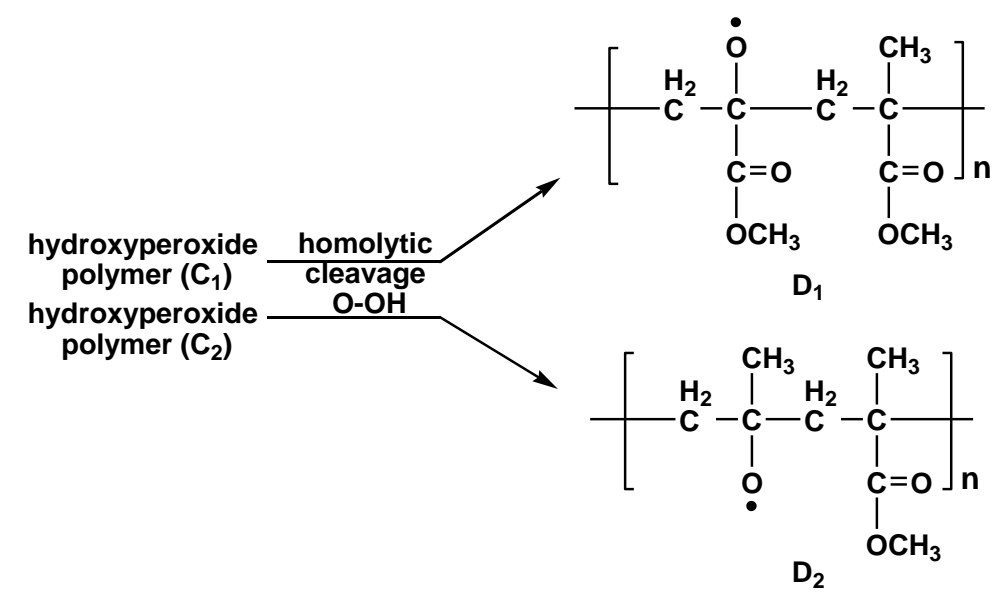

5. Alkoxy radical $\left(D_{1}, D_{2}\right)$ undergo a number of other reactions such as:

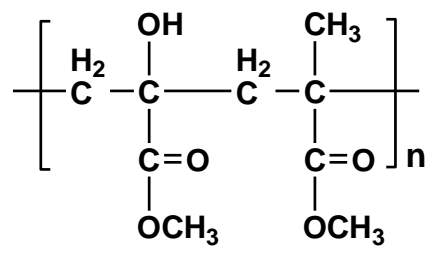

$\mathrm{E}_{1}$
5A) Abstraction of hydrogen atom to produce polymeric alcohols $\left(\mathrm{E}_{1}, \mathrm{E}_{2}\right)$.

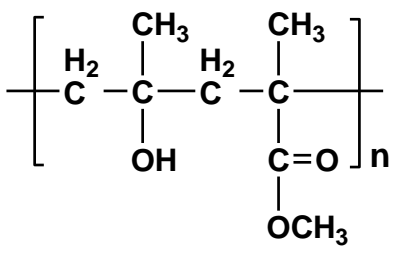

$\mathrm{E}_{2}$

5B) $\beta$ - scission reaction to produce ketonic polymers $\left(\mathrm{F}_{1}, \mathrm{~F}_{2}\right)$, respectively.

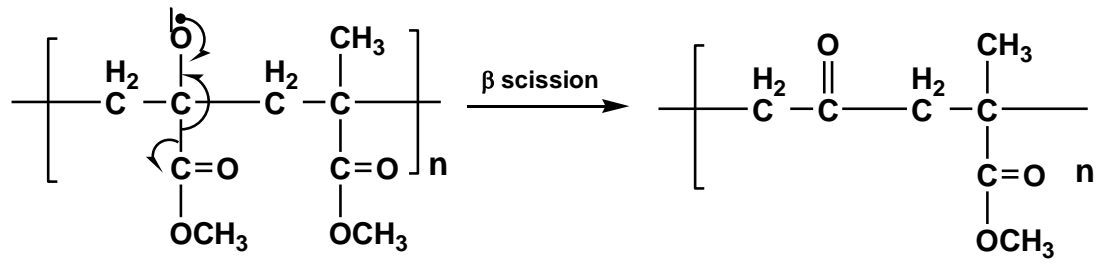

$\mathrm{D}_{1}$<smiles>COC(=O)C1(C)C2CCC(CC2(C)C)C1(C)C</smiles>

The formation of ketonic group in polymeric chain play an important role in further mechanism of oxidative degradation of
$F_{1}$<smiles>COC(=O)C(C)(CC(=O)CC(C)(C)C)C1(C)CCCCC1</smiles><smiles>COC(=O)CC(C)(C)CC(C)(C(=O)OC)C(C)(C)C(=O)OC</smiles> 
The oxazepine-oxadiazole compounds were used as additives for the photostabilization of PMMA films. In order to study the photochemical activity of these additives for the photostabilization of PMMA films, the hydroxyl index was monitored with irradiation time using IR spectrophotometry. The irradiation of PMMA films with UV light of wavelength, $\lambda=313 \mathrm{~nm}$ led to a clear change in the FTIR spectrum. Appearance of bands in $3430 \mathrm{~cm}^{-1}$ was attributed to the formation of the hydroxyl group. The absorption of the hydroxyl group was used to follow the extent of polymer degradation during irradiation. This absorption was calculated as hydroxyl index. It is reasonable to assume that the growth of hydroxyl index is a measure to the extent of degradation. However, in Fig. (1), the $\mathrm{I}_{\mathrm{OH}}$ of [4], [3], [2] and [1] showed lower growth rate with irradiation time with respect to the PMMA control film without additives. Since the growth of hydroxyl index with irradiation time is lower than PMMA blank, as seen in Fig. (1), it is suitable to conclude that these additives might be considered as photostabilizers of PMMA polymer. Efficient photostabilizer shows a longer induction period. Therefore, the [1] is considering as the most active photostabilizer, followed by [2], [3] and [4] which is the least active.

\subsection{Variation of PMMA molecular weight during photolysis in the presence of by 1,3-Oxazepine-1,3,4-oxadiazole compounds.}

Analysis of the relative changes in viscosity average molecular weight $\left(\overline{\mathrm{M}}_{\mathrm{v}}\right)$ has been shown to provide a versatile test for random chain scission. Fig. (2) shows the plot of $\left(\overline{\mathrm{M}}_{\mathrm{v}}\right)$ versus irradiation time for (PMMA) film with and without $0.5 \%$ (wt/wt) of the selected additives, with absorbed light intensity of $1.052 \times 10^{-8}$ ein. $\mathrm{dm}^{-3} \cdot \mathrm{s}^{-1}$. $\overline{\mathrm{M}} \mathrm{v}$ is measured using Eq. (3) with benzene as a solvent at $25^{\circ} \mathrm{C}$. It is worth mentioning that traces of the films with additives are not soluble in chloroform indicating that crosslinking or branching in the (PMMA) chain does occur during the course of photolysis. For better support of this view, the number of average chain scission (average number cut per single chain) $(S)^{(16)}$ was calculated using the relation:

$S=\frac{\bar{M}_{\mathrm{v}, 0}}{\bar{M}_{\mathrm{v}, t}}-1$

where $\overline{\mathrm{M}}_{\mathrm{v}, \mathrm{o}}$ and $\overline{\mathrm{M}}_{\mathrm{v}, \mathrm{t}}$ are viscosity average molecular weight at initial (o) and t irradiation time respectively. The plot of (S) versus time is shown in Fig.(3). The curve indicates an increase in the degree of branching such as that might arise from cross-linking occurrence. It is observed that insoluble material was formed during irradiation which provided an additional evidences to the idea that crosslinking does occur. For randomly distributed weak bond links ${ }^{(17)}$ which break rapidly in the initial stages of photodegradation, the degree of deterioration $(\alpha)$ is given as:

$\alpha=\frac{m \cdot s}{\bar{M}_{v}}$

where $\mathrm{m}$ is the initial molecular weight. The plot of $\alpha$ as a function of irradiation time is shown in Fig.(4). The values of a of the irradiated samples are higher when additives are absent and lower in the presence of additives compared to the corresponding values of the additive free PMMA. In the initial stages of photodegradation of PMMA, the value of $(\alpha)$ increases rapidly with time, these indicators indicates a random breaking of bonds in the polymer chain. Another way of degradation reaction characterization is the measurement of the quantum yield of the chain scission $\left(\Phi_{\mathrm{cs}}\right)^{(18)}$. The quantum yield for chain scission was calculated for PMMA films with and without $0.5 \% \quad(\mathrm{wt} / \mathrm{wt})$ of additive mentioned above using relation (6). The Фcs values for complexes are tabulated in Table (1). 
Table (1)

Quantum yield $\left(\Phi_{c s}\right)$ for the chain scission for PMMA films (40 $\mu m$ ) thickness with and without $0.5(w t / w t)$ additive after 250 hrs. irradiation time.

\begin{tabular}{|c|c|}
\hline $\begin{array}{c}\text { Additive } \\
(\mathbf{0 . 5} \% \text { wt })\end{array}$ & $\begin{array}{c}\text { Quantum yield of } \\
\text { main chain scission } \\
\left(\Phi_{c s}\right)\end{array}$ \\
\hline \hline PMMA +[4] & $4.40 \mathrm{E}-05$ \\
\hline \hline PMMA +[3] & $7.24 \mathrm{E}-05$ \\
\hline \hline PMMA +[2] & $7.58 \mathrm{E}-05$ \\
\hline \hline PMMA +[1] & $8.76 \mathrm{E}-05$ \\
\hline \hline PMMA (blank) & $4.54 \mathrm{E}-04$ \\
\hline
\end{tabular}

The $\Phi_{\mathrm{cs}}$ values for PMMA films in the presence of additive are less than that of additive free PMMA (blank), which increase in the order: [1]> [2]> [3]> [4].

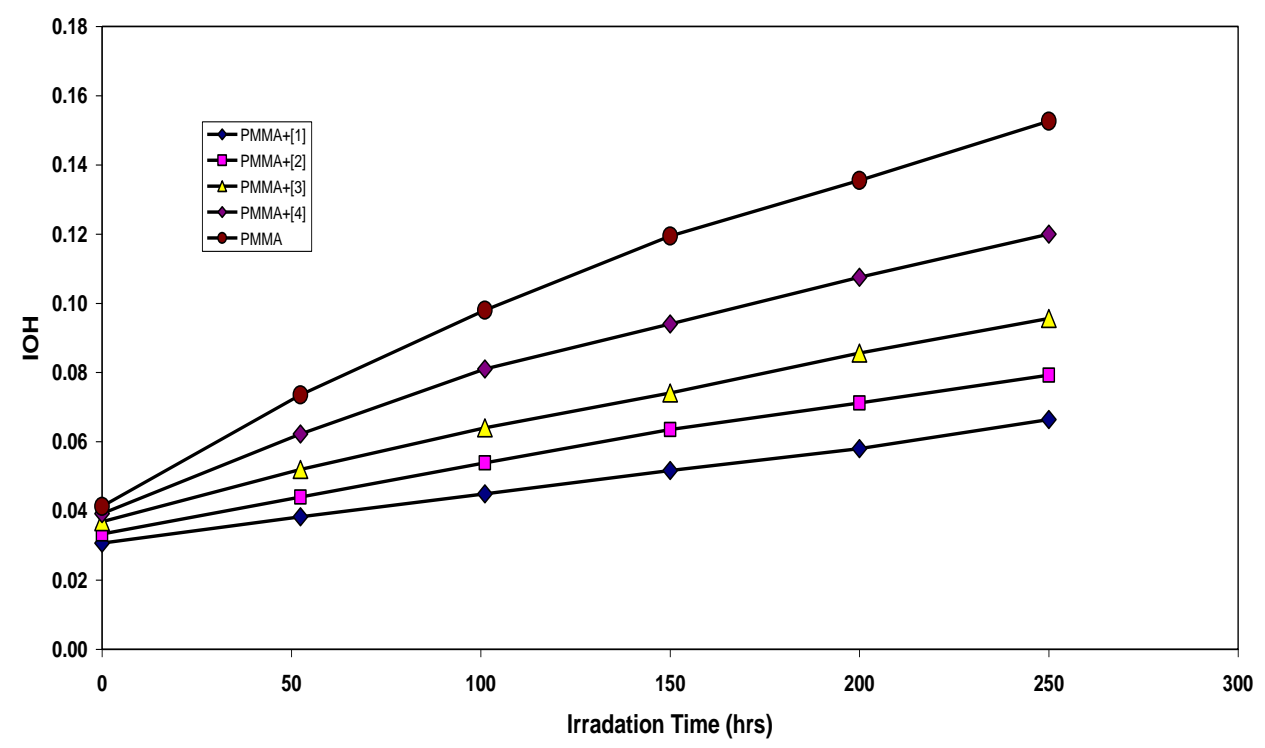

Fig.(1) The relationship between the hydroxyl index and irradiation time for PMMA films (40 $\mu$ m thickness). Containing different additives, concentration of additives are fixed at $0.5 \%$ by weight.

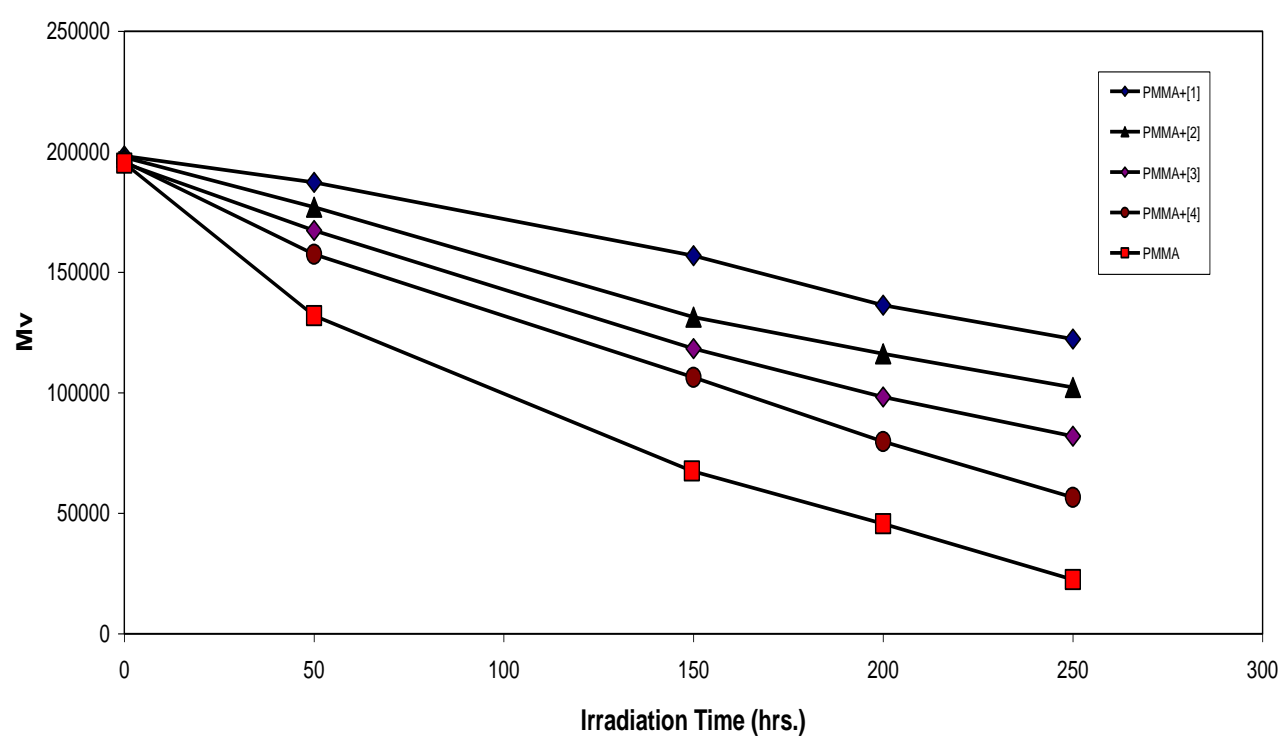

Fig.(2) Changes in the viscosity average molecular weight during irradiation of PMMA films (40 $\mu \mathrm{m})$. 


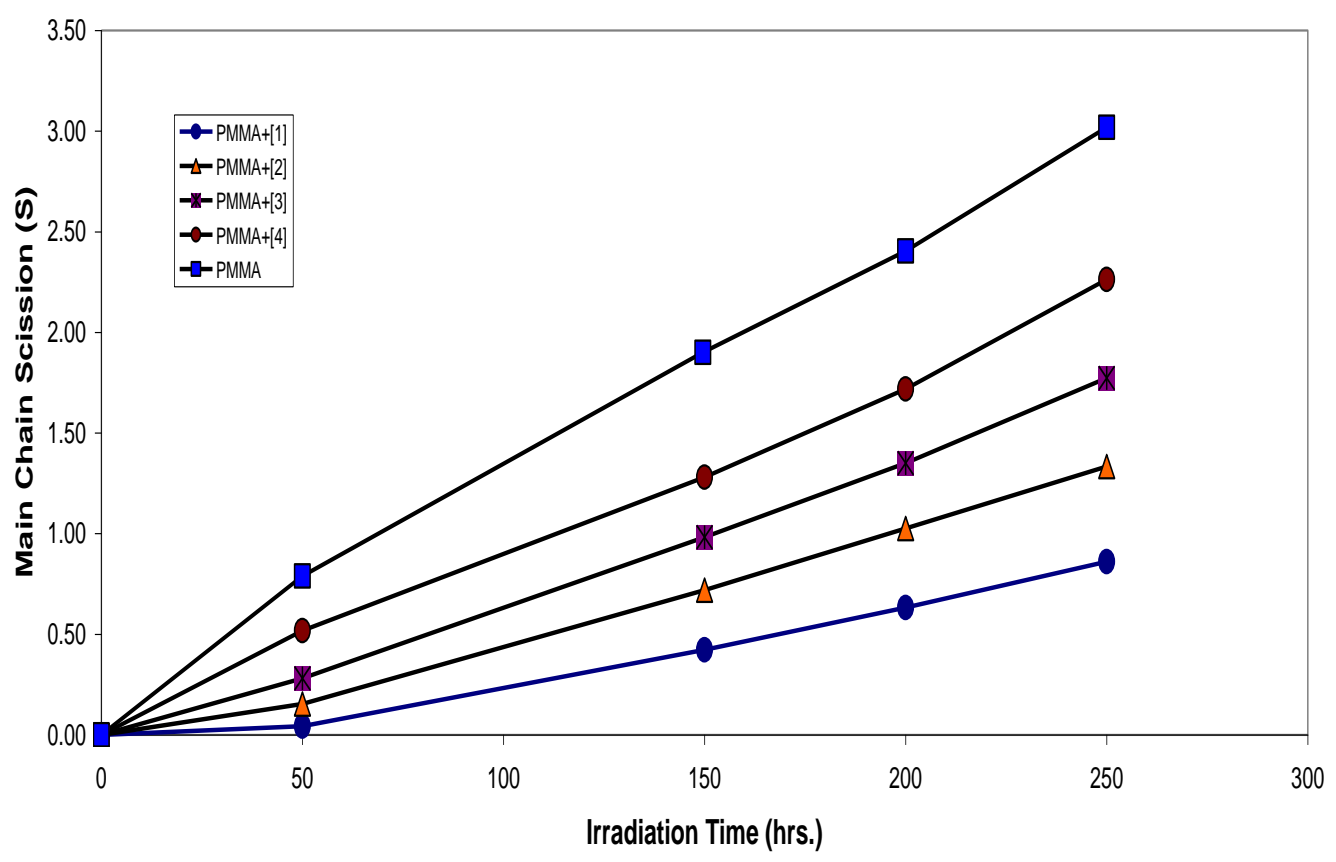

Fig.(3) Changes in the main chain scission (S) during irradiation of PMMA films (40 $\mu \mathrm{m})$ (control) and with 0.5 wt\% of additives.

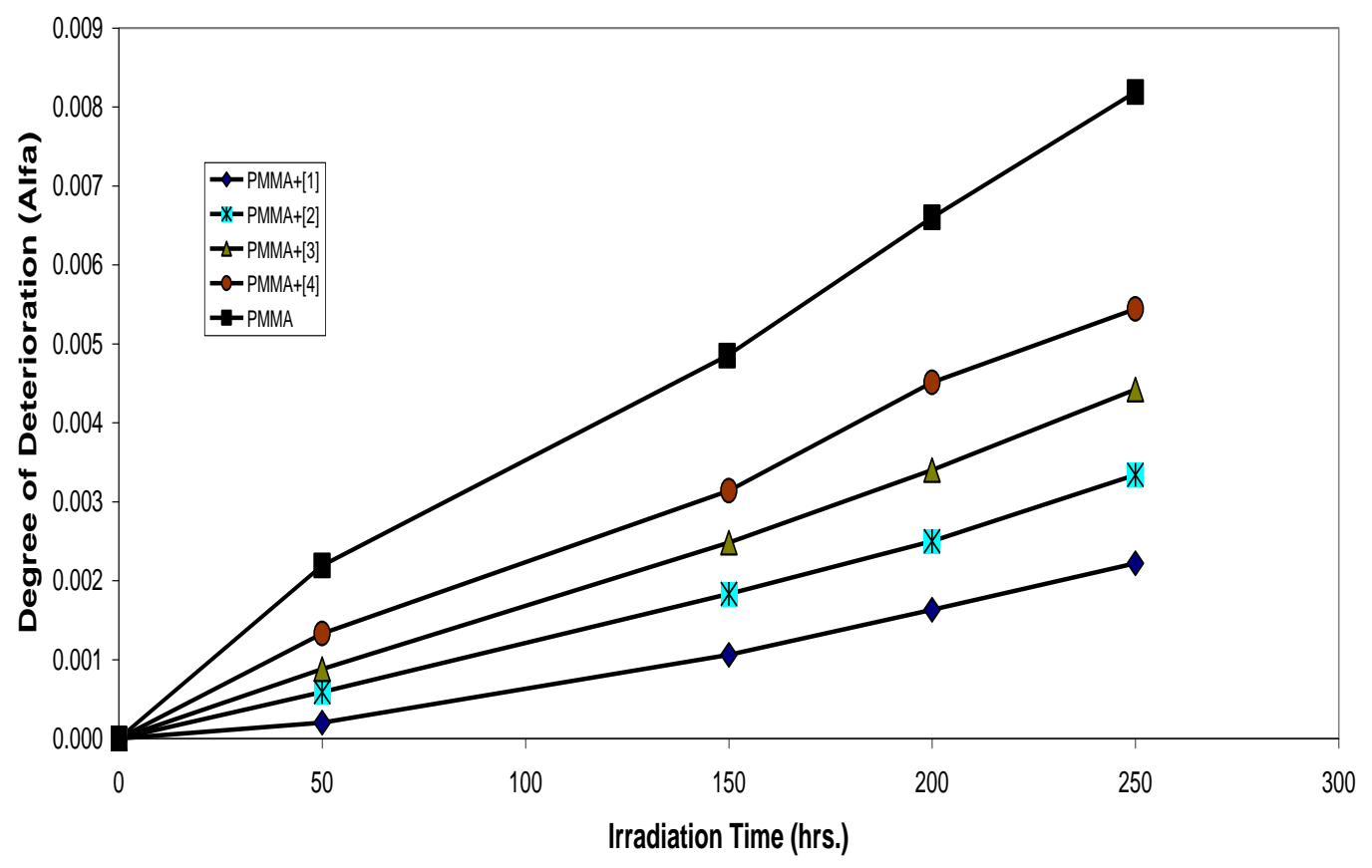

Fig.(4) Changes in the degree of deterioration during irradiation of PMMA films (40 $\mu \mathrm{m})$ (control) and with 0.5 wt\% of additives.

4.2 Suggested mechanisms of

photostabilization of PMMA by 1,3-

Oxazepine compounds

Through the overall results obtained, the efficiency 1,3-Oxazepine compounds as photostabilizers for PMMA films can be arranged according to the change in the hydroxyl concentration as a reference for the comparison as shown in Fig.(1). as follows:

$[1]>[2]>[3]>[4]$

1,3-Oxazepine stabilize PMMA by different mechanisms such as UV absorber, screener or by radical scavenger. These stabilizers provide very good long-term stability and are usually referred to these 
mechanisms. The most probable mechanisms involved in a photostabilization is the The hydroxyl group of the additive might acts as radical scavenger for photostabilization process. Therefore this Schiff bases, besides acting as UV absorber they may also act as radical scavenger additives ${ }^{(19)}$, Scheme (1).

The rings of oxazepine play a role in the mechanism of the stabilizer process by acting as UV absorber. The UV light absorption by these additives containing 1,3,4-thiadiazole dissipates the UV energy to harmless heat energy Scheme (2).

The ring of 1,3,4-oxadiazole in this compound plays a role in the mechanism of the stabilizer process by acting as UV absorber. The UV light absorption by these additives containing 1,3,4 -oxadiazole dissipates the UV energy to harmless heat energy scheme (3), which support these compounds as photostabilizer ${ }^{(20-24)}$.

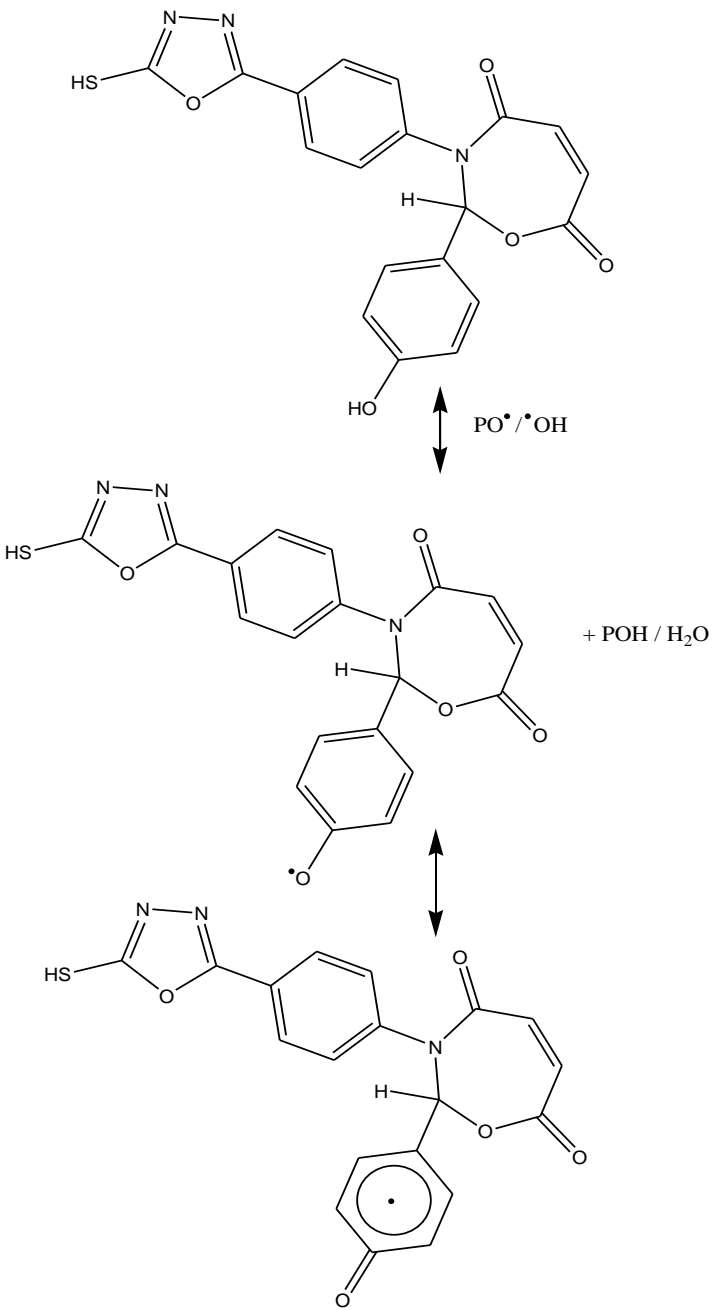

Scheme (4) The suggested mechanism of photostabilization of PMMA by compounds [1] as radical scavenger.

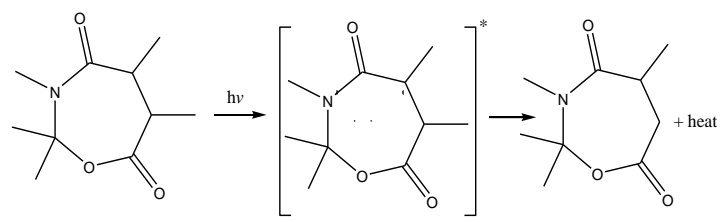

Scheme (5) Suggested mechanism of photostabilization of 1,3-Oxazepine ring as UV absorber.

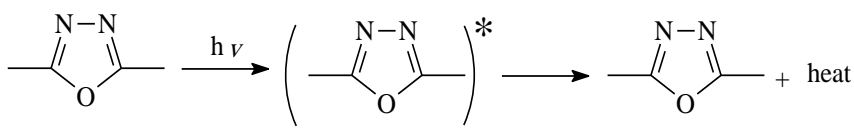

Scheme (5) Suggested mechanism of photostabilization of 1,3,4- oxadiazole ring as UV absorber.

\section{Conclusions}

In the work described in this paper, the photostabilization of PMMA films using 1,3-Oxazepine compounds were studied. These additives behave successfully as photostabilizer for PMMA films. The additives take the following order in photostabilization activity according to their decrease in hydroxyl index for PMMA films.

$[1]>[2]>[3]>[4]$

These additives stabilize the PMMA films through UV absorption or screening, peroxide decomposer and radical scavenger mechanisms. The [1] compound was found to be the more efficient in photostabilization process according to the photostability and mechanisms mentioned above. These mechanisms support the idea of using 1,3-Oxazepine compounds as commercial stabilizer for PMMA.

\section{References}

[1] Khalafi-Nezhad A. and Aboulghasem H., Microwave Enhanced Knoevenagel Condensation of Barbituric Acid with Aromatic Aldehydes on Basic AIumina, Iran. J. Chem. \& Chem. Eng. 20(1): pp. 9$11 ; 2001$.

[2] Anna C., Crstina L., Antonino R., Roberto R., Paolo V., G. Romano G., Sara B. and Carla V., New New "Green" Approaches to the Synthesis of Pyrazole Derivatives Molecules, 12; pp. 1482-1495; 2007. 
[3] Bougrin K., Loupy A., A microwave assisted solvent free heterocyclic synthesis, J. Photochem. Photobiol. C., Photochem. Rev., 6, PP. 139-167; 2005.

[4] Frank P., Grish K. and B. kalluraya, Solvent-free microwave-assisted synthesis of oxadiazoles containing imidazole moiety J. Chem. Sci., 119 (1): PP. 41-46: 2007.

[5] Loupy A., Bram G. and Sansoulet J., New J. Chem. Lett., 386,7029(1992).

[6] Andrady, A., Hamid, S., Hu, X., Torikai, A., "Effects of increased solar ultraviolet radiation on materials in Environmental Effects of Ozone Depletion", J. Photochem. Photobiol. B Biol. 46, 96-103, 1988.

[7] Andrady, A., Searle, N., Photodegradation of rigid PVC formulations. II. Spectral sensitivity to light-induced yellowing by polychromatic light, "J. Appl. Poly. Sci." 37; PP. 2789-2802; 1989.

[8] Grassie, N., Scott, G., "Polymer Degradation and Stabilization". Cambridge University Press, London, 1985.

[9] Harper, D., McKellar, N., Turner, P., Photostabilizing effect of Ni (II) chelates in polymers. Effect of diamagnetic chelates on polypropylene phosphorescence, "J.Appl.Polym.Sci." 18: 2802-2805; 1974.

[10] Entesar Jarallh Fadel "M.Sc. Thesis" Tikrit University, Tikrit, Iraq, 2010.

[11] Abed Mohameed Daher , H Al-Jibory "Ph.D. Thesis" Tikrit University, Tikrit, Iraq (2010).

[12] Rapek, J., Randy, B., "Photodegradation, Photo-oxidation and Photostabilization of polymers, 1975.

[13] Mark, J., "Physical Properties of Polymers Handbook". Springer, New York, 1988.

[14] Mori, F., Koyama, M., Oki, Y., 1997. Studies on photodegradation of poly (vinyl chloride) (part I), "Die Angewandte Makomolekulare Chemie" 64 (1); 89-99; 2007.

[15] Nakajima, N., Sadeghi, M., Kyu, T., Photodegradation of poly(methyl methacrylate) by monochromatic light: Quantum yield, effect of wavelengths, and light intensity, "J. Appl. Poly. Sci." 41; 889-363; 1990.
[16] Shyichuk, A., White, J., Analysis of chain -scssion and crosslinking rates in the photo -oxidation of polystyrene, "H. Appl. Poly. Sci." 77(13); 3015-3023; 2000.

[17] Gugumus, F., 1990. "Mechnism of Polymer Degradation and Stabilization". Elsevier, Amsterdam, 1990.

[18] Salimon, J., Salih, N., Yousif, E., Hameed, A., Ibraheem, H., 210. Synthesis, characterization and biological activity of schiff bases of 2, 5-dimercapto-1,3,4thiadiazole, "Aut. J. Basic Appl. Sci." 4(7), 2016-2021; 2010.

[19] Rasheed, R., Mansoor, H., Yousif, E., Hameed, A., Farina, Y., Graisa, A., 2009. Photostabilizing of pvc films by 2-(aryl)-5[4-(aryloxy)-phenyl]-1,3,4-oxadiazole compounds, "Eur. J. Sci. Res". 30; 464477; 2009.

[20] Yousif, E., Aliwi, M., Ameer, A., Ukal, J., Improved photostability of PVC films in the presence of 2-thioacetic acid - 5phenyl - 1, 3, 4 -oxadiazole complexes, "Turk. J. Chem." 33, 339-410; 2009.

[21] Yousif, E., Hameed, A., Rasheed, R., Mansoor, H., Farina, Y., Graisa, A., Salih, N., Salimon, J. Synthesis and Photostability Study of Some Modified Poly(vinyl chloride) Containing Pendant Benzothiazole and Benzimidozole Ring. Int. J. Chem., 2(1): 65-80; 2010.

[22] Yousif, E., Salimon, J., Salih, N., Ahmed, A., Improvement of the photostabilization of PMMA films in the presence $2 \mathrm{~N}$ salicylidene-5-(substituted)-1,3,4thiadiazole, J. King Saud University (Science). 24: 11-17; 2012.

[23] Yousif, E., Salih, N., Salimon, J., Improvement of the photostabilization of PVC films in the presence of thioacetic acid benzothiazole complexes. The Malaysian J. Analy. Sci. 15(1):81-92; 2011.

[24]Yousif, E., Salih, N., Salimon, J.. Improvement of the Photostabilization of PVC Films in the Presence of $2 \mathrm{~N}$ Salicylidene-5-(Substituted)-1,3,4Thiadiazole. J. Appl. Poly. Sci. 120: $2207-$ 2214, 2011. 


\section{الخلاصة}

لقد تضمن البحث تحضير أربع مركبات حلقية غير

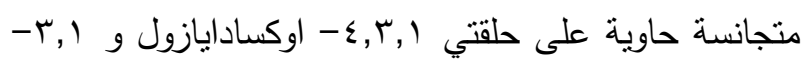

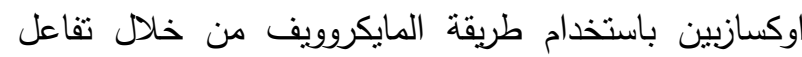

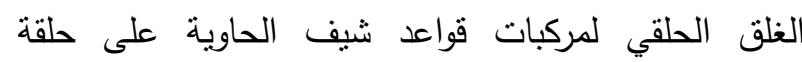

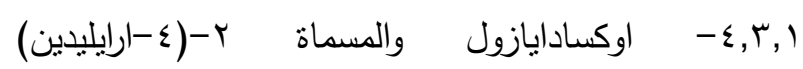

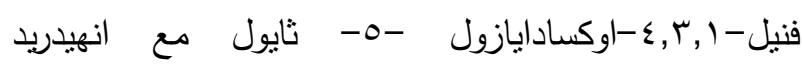

FT-) الماليك وشخصت المركبات المحضرة بالطرق الطيفية

(IR, H1-NMR وقد دلت النتائج المستحصلة على صحة بلى

التراكيب. ودرست الثباتية الضوئية لرقائق بولي (مثنيل ميثا

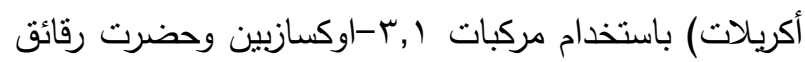

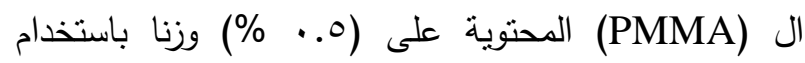

طريقة (Casting) باستخدام مذيب الكلوروفورم وقد تم منابعة

الثباتية الضوئية لهذه المركبات من خلال قياس المحتوى ليات

الهيروكسيلي مع زمن التشعيع كذلك نم منابعة التغيرات في

معدل الوزن الجزيئي لـ (PMMA) مع زمن التشعيع. منتوج

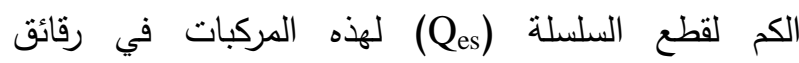

قد قيمت وقد وجد له معدل القيمة بين (PMMA)

والنتائج المستحصلة تشير

بان سرعة الثباتية لرقائق (PMMA) بوجود المضافات - 1 (PMAX)

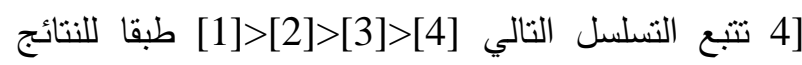

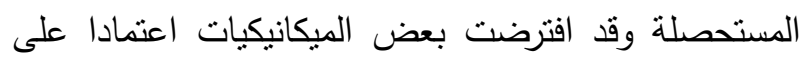

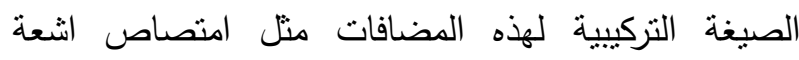

،تقكل البيروكسيد وامتصاص الجذور الحرة. 